\title{
Anisotropy of mechanical properties in quaternary Al-Li-Cu-Mg alloys
}

\author{
N ESWARA PRASAD and G MALAKONDAIAH \\ Defence Metallurgical Research Laboratory, P.O. Kanchanbagh, Hyderabad 500258 , India
}

MS received 29 January 1992; revised 27 March 1992

\begin{abstract}
Considerable anisotropy in the mechanical properties of quaternary $\mathrm{Al}-\mathrm{Li}-$ $\mathrm{Cu}-\mathrm{Mg}$ alloys was observed in both plate and sheet products. These alloys showed more than $100 \%$ increase in tensile ductility in the test direction oriented at $45-60^{\circ}$ to the rolling direction as compared to that in the rolling direction (longitudinal, L). A concomitant decrease in strength was also found. These alloys exhibit superior low cycle fatigue resistance in the long-transverse (LT) direction as compared to the longitudinal (L) direction. Another observation is the occurrence of strength differential (S-D), which is seen to be directional. The trends in S-D are similar under monotonic as well as cyclic loading conditions. The fracture resistance is also highly anisotropic. An attempt is made here to correlate the observed anisotropy in the mechanical behaviour of these alloys with the microstructure and crystallographic texture.
\end{abstract}

Keywords. Quaternary $\mathrm{Al}-\mathrm{Li}-\mathrm{Cu}-\mathrm{Mg}$ alloys; microstructure; texture; anisotropy; tensile; low cycle fatigue; strength differential; fracture resistance.

\section{Introduction}

Aluminium-lithium alloys are candidate materials for aircraft structural applications. These alloys possess superior specific modulus and strength as well as fatigue crack growth resistance as compared to the conventional $2 \mathrm{XXX}$ and $7 \mathrm{XXX}$ aircraft structural aluminium alloys (Baker et al 1986). On the other hand, significant improvement in ductility and fracture resistance needs to be achieved if these alloys were to replace the conventional aircraft structural aluminium alloys. Numerous attempts have been made in recent years to modify the alloy chemistry, processing schedules and thermomechanical treatments to achieve improved strength-toughness combination (Gregson and Flower 1985; Jata and Starke 1986). However, studies on the anisotropy in mechanical properties of these alloys are mostly confined to the tensile properties (Doorbar et al 1986; Peel et al 1986, 1987; Takahashi et al 1987). The present paper reports the results of a comprehensive study on the anisotropy in the mechanical properties of $8090 \mathrm{Al}-\mathrm{Li}-\mathrm{Cu}-\mathrm{Mg}$ alloys.

\section{Experimental}

The quaternary $\mathrm{Al}-\mathrm{Li} 8090$ alloys have the nominal composition, by $w \mathrm{t} \%, 2 \cdot 2-2 \cdot 51 \mathrm{Li}$, $1-1.4 \mathrm{Cu}, 0.7-1 \mathrm{Mg}, 0.02-0.16 \mathrm{Zr}$ and the balance aluminium. Lital $\mathrm{C}$ contains higher $\mathrm{Cu}$ and $\mathrm{Mg}$ and lower $\mathrm{Zr}$ as compared to Lital $\mathrm{A}$. Various product forms, namely the Lital A plates ( 8 and $12.5 \mathrm{~mm}$ thickness) in T8E51 condition, Lital A sheets ( 2 and $3 \mathrm{~mm}$ thickness) in T6 condition, Lital C sheets (1.6 and $3 \mathrm{~mm}$ thickness) in T81 condition and Lital $\mathrm{C}$ sheet $(1.6 \mathrm{~mm}$ thickness) in $\mathrm{T} 3$ condition were tested in the as-received condition. 
Tensile tests were conducted on specimens oriented differently with respect to the rolling direction. In the case of $12.5 \mathrm{~mm}$ thick plate, specimens with $25 \mathrm{~mm}$ gauge length and $6.5 \mathrm{~mm}$ gauge diameter were used. On the other hand, flat tensile specimens with $25 \mathrm{~mm}$ gauge length and $8 \mathrm{~mm}$ width were employed to determine the tensile properties of the sheet products.

Fully-reversed, total-strain controlled low cycle fatigue (LCF) tests were conducted on MTS 880 servohydraulic test system using specimens of $15 \mathrm{~mm}$ gauge length and $6.5 \mathrm{~mm}$ gauge diameter. The strain was monitored using a $10 \mathrm{~mm}$ axial extensometer.

Plane-strain fracture toughness $\left(K_{I c}\right)$ tests were conducted on $12.5 \mathrm{~mm}$ thick plate in $\mathrm{L}-\mathrm{T}$ (the notch being perpendicular to the rolling direction) and $\mathrm{T}-\mathrm{L}$ (the notch being parallel to the rolling direction) orientations. Standard $12.5 \mathrm{~mm}$ thick compact tension specimens were used. For sheet products, the plane-stress fracture toughness $\left(K_{c}\right)$ was evaluated in both $\mathrm{L}-\mathrm{T}$ and $\mathrm{T}-\mathrm{L}$ orientations using specimens of $101.6 \mathrm{~mm}$ width and half-height to width ratio of 0.6 . Fracture toughness tests were conducted following ASTM standards E-399 $\left(K_{I c}\right)$ and E-516 $\left(K_{c}\right)$ on computer-controlled servohydraulic MTS 880 and Instron 8500 test systems.

Crystallographic texture of both plate and sheet products was evaluated in the as-received condition. Three incomplete $\{111\},\{100\}$ and $\{220\}$ pole figures up to a maximum tilting angle of $80-85^{\circ}$ were obtained by $\mathrm{X}$-ray diffraction technique using Siemens AG texture goniometer fitted with a D-500 diffractometer with Fe radiation.

\section{Results and discussion}

\subsection{Microstructure and texture}

The alloys in the as-received condition possess elongated, pancake structure with partial recrystallization. The optical micrograph of $12.5 \mathrm{~mm}$ thick plate, shown in figure 1a, reveals a wide variation in grain width and aspect ratio in three orthogonal directions. Such an anisotropy in grain structure was also seen to be present in the other plate and sheet products under consideration. As the grain width decreases, the grain aspect ratio increases. Among the products under consideration, Lital $\mathrm{C}$ sheets were characterized by predominantly recrystallized grain structure (figure $1 \mathrm{~b}$ ). At higher resolutions, the microstructure consists of spherical, dense and uniformly distributed $\mathrm{Al}_{3} \mathrm{Li}\left(\delta^{\prime}\right.$, the strengthening phase) and lenticular $\mathrm{Al}_{2} \mathrm{CuMg}$ (S, the phase leading to slip homogenization) precipitates. The $\mathrm{S}$ phase is nearly absent in Lital $\mathrm{A}$ sheet products of 2 and $3 \mathrm{~mm}$ thickness in T6 condition and Lital C sheet of $3 \mathrm{~mm}$ in T81 condition. A strong cross-rolled texture was observed in the $12.5 \mathrm{~mm}$ thickness plate, while the $8 \mathrm{~mm}$ thick plate and other sheet products exhibited predominant straight-rolled texture. The microstructure and texture characteristics of the alloys are summarized in table 1.

\subsection{Orientation dependence of tensile properties}

The tensile properties of $8090 \mathrm{Al}-\mathrm{Li}$ alloys evaluated with specimens oriented differently with respect to the rolling direction are given in table 2 . Both the plate and sheet products exhibit significant anisotropy. As the orientation changes from 0 

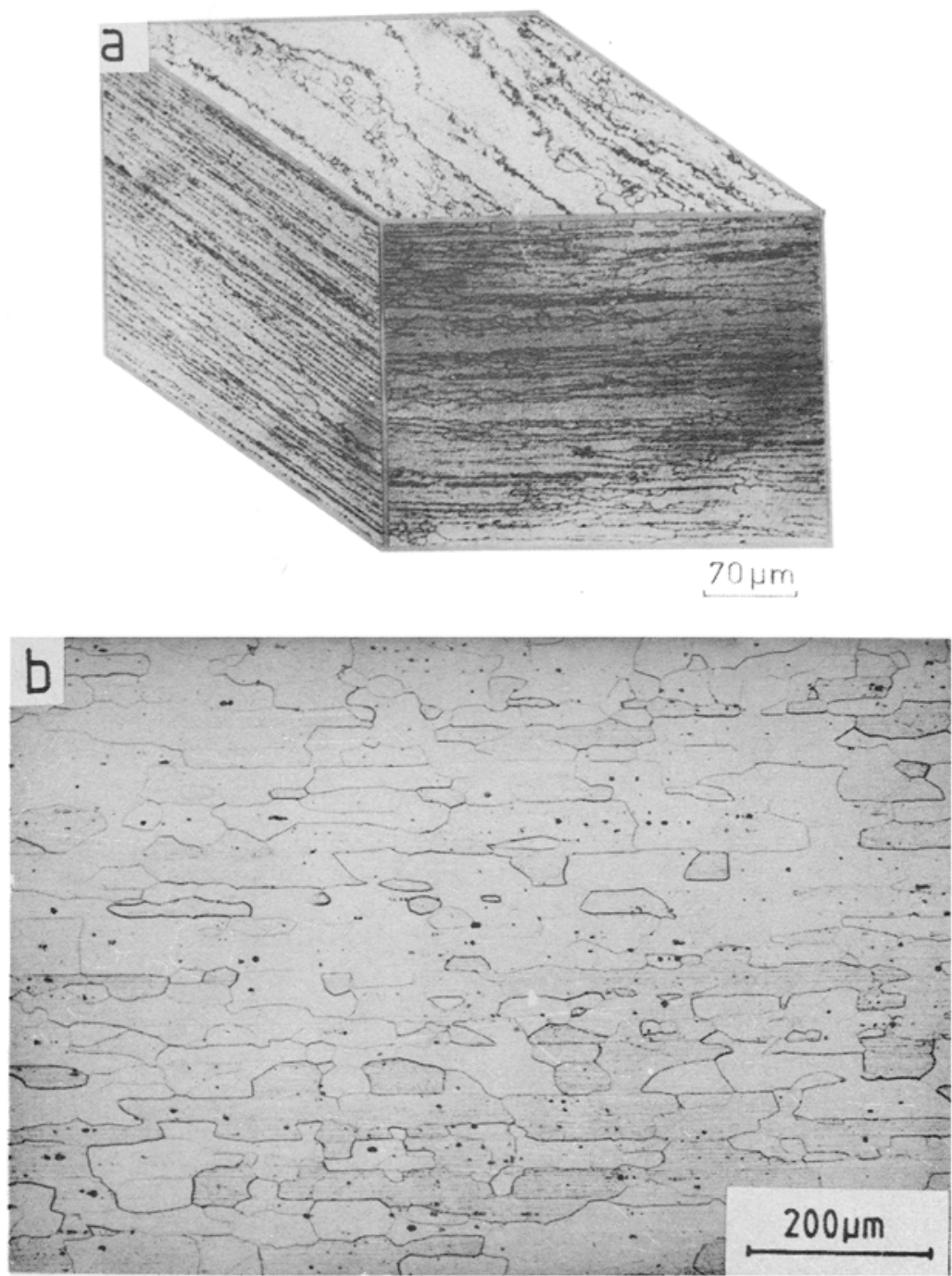

Figure 1. (a) Triplanar optical micrograph of Alcan 8090 plate of $12.5 \mathrm{~mm}$ thickness in T8E51 condition; (b) optical micrograph of Lital C-T81 in L direction showing recrystallized grain structure.

to $60^{\circ}$, the strength decreases and the ductility increases. In the case of $12.5 \mathrm{~mm}$ thick plate, the maximum decrease in yield strength is $21 \%$ (occurring at $60^{\circ}$ ), while the UTS decreased by $14 \%$ (occurring at $45^{\circ}$ ). The corresponding increase in ductility is around $110 \%$. Both work-hardening coefficient $(n)$ and uniform elongation $\left(\varepsilon_{w}\right)$ attain maximum values at $45-60^{\circ}$ to the rolling direction. A similar trend in the orientation dependence of tensile properties, though to a varying degree, has been observed with other $8090 \mathrm{Al}-\mathrm{Li}$ alloy products (table 2 ).

The $\mathrm{Al}-\mathrm{Li}$ alloys under consideration, containing $\mathrm{Li}, \mathrm{Cu}$ and $\mathrm{Mg}$ as the major alloying additions, exhibit varying degree of serrated plastic flow depending upon the aging treatment and thereby the concentration of $\mathrm{Li}, \mathrm{Cu}$ and $\mathrm{Mg}$ in the solid solution and the 


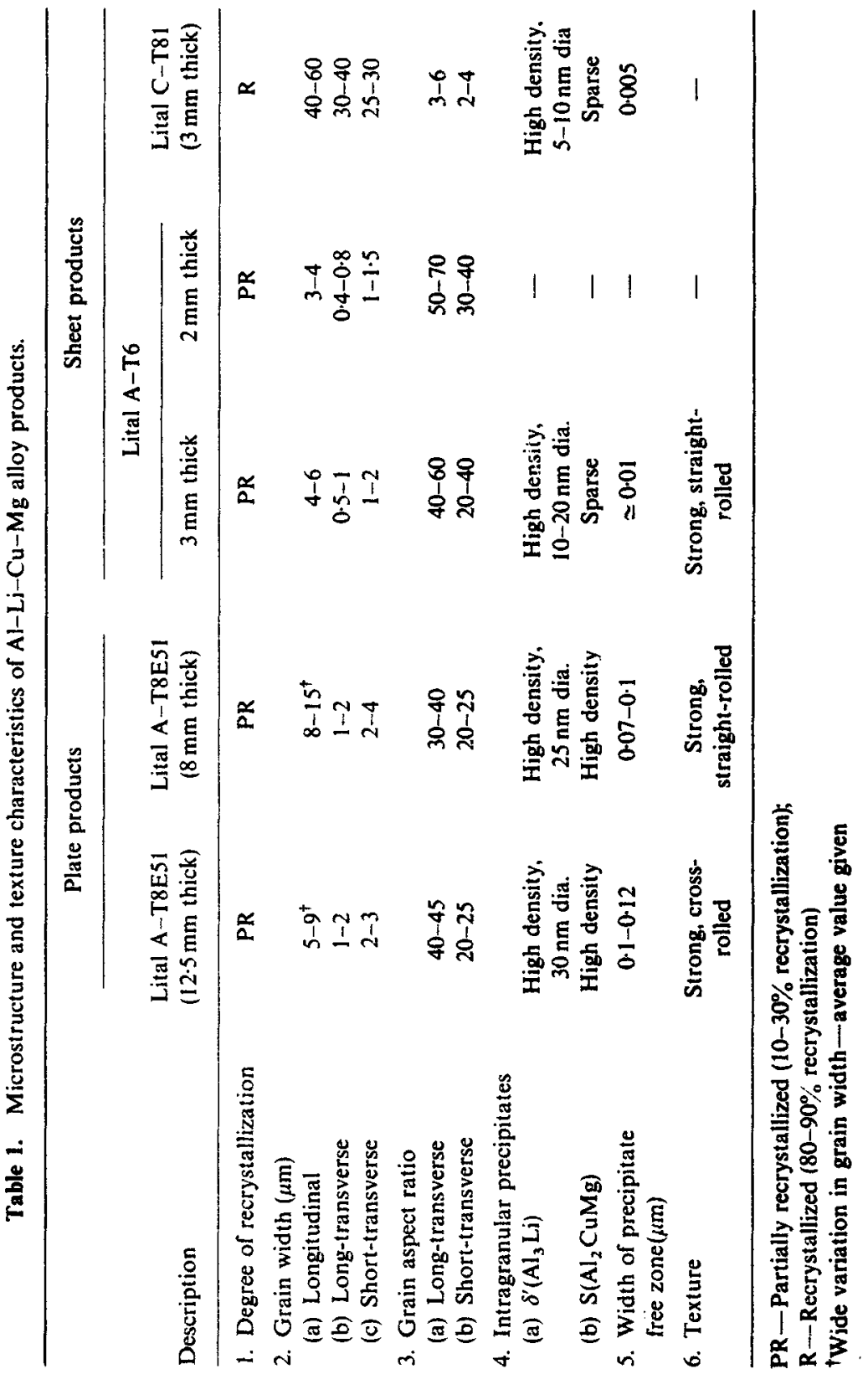


Table 2. Orientation dependence of tensile properties of $\mathrm{Al}-\mathrm{Li} 8090$ alloys.

\begin{tabular}{|c|c|c|c|c|c|c|}
\hline \multirow{2}{*}{$\begin{array}{l}\text { Alloy } \\
\text { designation }\end{array}$} & \multirow[b]{2}{*}{ Property } & \multicolumn{5}{|c|}{$\begin{array}{l}\text { Specimen orientation with respect } \\
\text { to the rolling direction, (deg.) }\end{array}$} \\
\hline & & $0(\mathrm{~L})$ & 30 & 45 & 60 & $90(\mathrm{LT})$ \\
\hline \multirow{6}{*}{$\begin{array}{l}\text { PLATES } \\
\text { Lital A-T8E51 } \\
\text { (12.5 mm thick) }\end{array}$} & & & & & & \\
\hline & $0.2 \%$ Y.S., MPa & 485 & 447 & 393 & 382 & 467 \\
\hline & UTS., MPa & 555 & 509 & 478 & 513 & 534 \\
\hline & Elongation (25 mm GL) & 0.054 & 0.061 & $0 \cdot 115$ & 0.096 & 0.07 \\
\hline & Uniform elongation & 0.054 & 0.058 & 0.075 & 0.07 & 0.06 \\
\hline & $\mathrm{n}$ & 0.053 & $0 \cdot 063$ & 0.077 & $0 \cdot 11$ & 0.05 \\
\hline \multirow{5}{*}{$\begin{array}{l}\text { Lital A-T8E51 } \\
(8 \mathrm{~mm} \text { thick })\end{array}$} & $0.2 \%$ Y.S., MPa & 471 & - & 370 & - & 457 \\
\hline & UTS., MPa & 561 & - & 472 & - & 547 \\
\hline & Elongation $(10 \mathrm{~mm} \mathrm{GL})$ & 0.05 & - & 0.057 & - & 0.075 \\
\hline & Uniform elongation & 0.05 & - & 0.057 & - & 0.07 \\
\hline & $\mathrm{n}$ & 0.065 & - & 0.09 & - & 0.068 \\
\hline \multicolumn{7}{|l|}{ SHEETS } \\
\hline Lital A-T6 & $0.2 \%$ Y.S., MPa & 456 & 424 & 352 & 350 & 432 \\
\hline \multirow[t]{4}{*}{ (3 mm thick) } & UTS., MPa & 528 & 487 & 476 & 464 & 538 \\
\hline & Elongation (25 mm GL) & $0.023^{*}$ & 0.044 & $0 \cdot 14$ & $0 \cdot 141$ & 0.062 \\
\hline & Uniform elongation & 0.023 & 0.044 & $0 \cdot 102$ & 0.096 & 0.062 \\
\hline & $\mathrm{n}$ & 0.068 & 0.058 & $0 \cdot 111$ & $0 \cdot 101$ & 0.086 \\
\hline Lital C-T81 & $0.2 \%$ Y.S., MPa & 355 & 326 & 324 & 315 & 310 \\
\hline \multirow[t]{4}{*}{ (1.6 mm thick) } & UTS., MPa & 452 & 461 & 448 & 450 & 449 \\
\hline & Elongation (25 mm GL) & 0.062 & $0 \cdot 104$ & 0.116 & $0 \cdot 10$ & $0 \cdot 10$ \\
\hline & Uniform elongation & 0.06 & 0.08 & 0.097 & 0.088 & 0.092 \\
\hline & $\mathrm{n}$ & $0 \cdot 108$ & $0 \cdot 114$ & $0 \cdot 107$ & $0 \cdot 123$ & 0.131 \\
\hline Lital C-T3 & $0.2 \%$ Y.S., MPa & 211 & 204 & 206 & 198 & 203 \\
\hline \multirow[t]{4}{*}{ (1.6 mm thick) } & UTS., MPa & 328 & 328 & 330 & 315 & 331 \\
\hline & Elongation (25 mm GL) & $0 \cdot 17$ & $0 \cdot 174$ & $0 \cdot 178$ & $0 \cdot 19$ & $0 \cdot 162$ \\
\hline & Uniform elongation & $0 \cdot 145$ & $0 \cdot 14$ & $0 \cdot 16$ & $0 \cdot 15$ & $0 \cdot 14$ \\
\hline & $\mathrm{n}$ & 0.16 & 0.161 & $0 \cdot 155$ & $0 \cdot 162$ & $0 \cdot 163$ \\
\hline
\end{tabular}

*Average of 3 tests. All the specimens failed in curvature

test specimen orientation. Serrated flow is more pronounced in Lital C in T3 condition as compared to Lital $\mathrm{A}$ in $\mathrm{T} 6$ condition and for a given material in specimens oriented at $45-60^{\circ}$ to the rolling direction (figure 2). The serrated plastic flow can be understood in terms of the interaction of solute elements with the dislocations resulting in Portevin-Le-Chatlier effect (Behnood and Evans 1989) and to progressive shearing of $\delta^{\prime}$ precipitates (Gregson et al 1988).

The directionality in tensile properties of $\mathrm{Al}-\mathrm{Li}$ alloys has been attributed to (i) crystallographic texture (Doorbar et al 1986; Gregson and Flower 1985; Peel et al 1986, 1987; Smith 1987; Welpmann et al 1984), (ii) mechanical fibring which includes grain anisotropy, degree of recrystallization, banding of small grains and directionality of coarse as well as fine inclusions (Wilson 1975; Forsyth and Stubbington 1975; Doorbar et al 1986; Peel et al 1986, 1987) and (iii) nature and distribution of strengthening precipitates (Dinsdale et al 1988; Lee and Kim 1989). In order to bring out the effect of various metallurgical factors on the tensile anisotropy in $8090 \mathrm{Al}-\mathrm{Li}$ alloys, the anisotropy data in table 2 are regrouped and presented in table 3 . An 

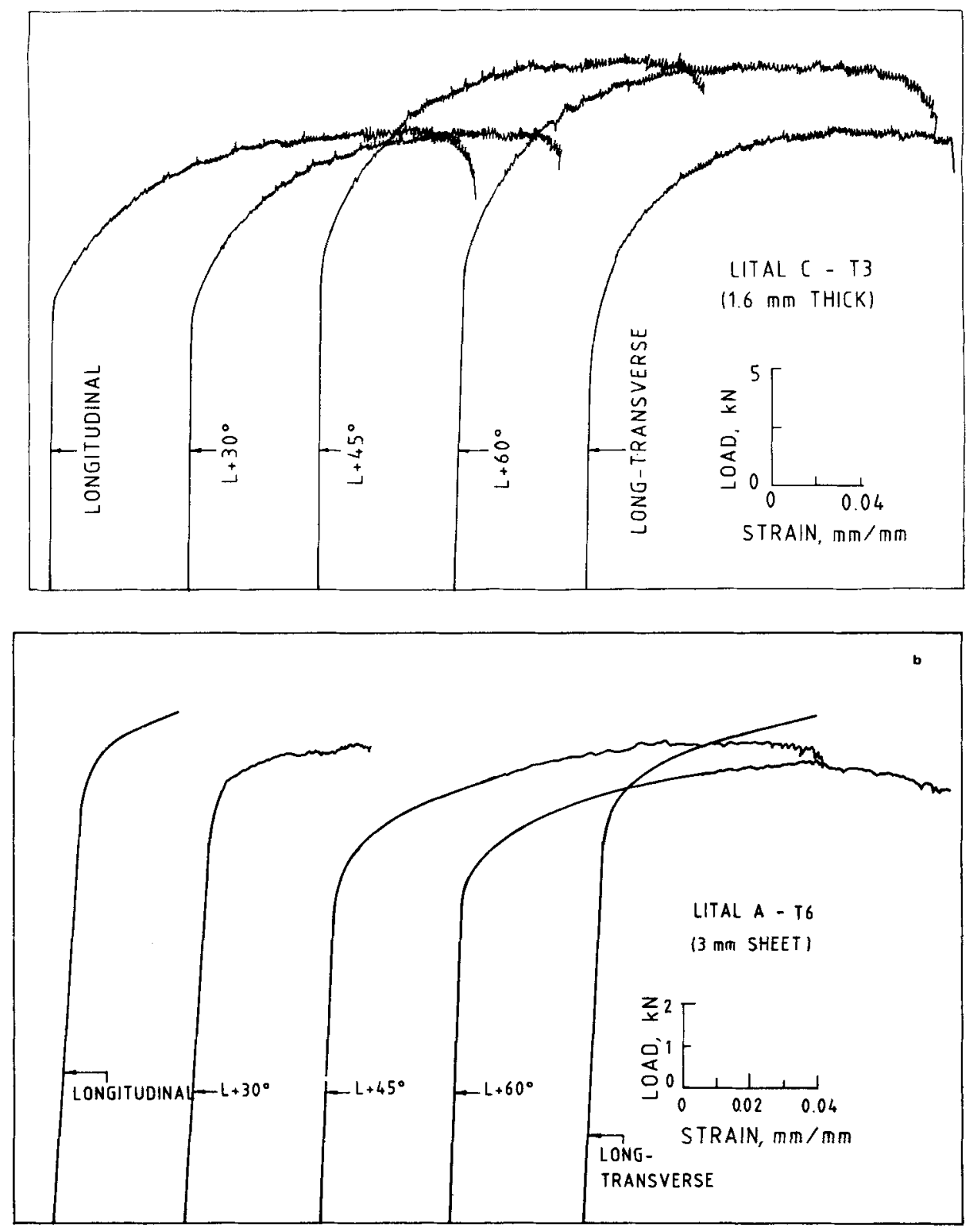

Figure 2. Load-elongation curves showing varied degrees of serrated plastic deformation in (a) Lital C-T3 and (b) Lital A-T6 sheets.

analysis of the data in table 3 reveals that the crystallographic texture and the degree of recrystallization have a pronounced effect on the anisotropy of these alloys.

The $\{111\}$ and $\{220\}$ pole figures obtained indicate that the commonly observed $\{110\}\langle 112\rangle$ hot-rolling texture is predominant in the cross-rolled $12.5 \mathrm{~mm}$ thick plate. On the other hand, the other $\mathrm{Al}-\mathrm{Li}$ alloy products now studied with straight-rolled texture possess an additional cold-rolled component of $\{112\}\langle 111\rangle$, which was seen to be more pronounced at thinner gauges. The textural observations are consistent 
Table 3. Metallurgical factors and the degree of anisotropy in tensile properties of Lital $\mathrm{A}$ and Lital $\mathrm{C}$ alloy products.

\begin{tabular}{|c|c|c|c|c|c|}
\hline Description & $\begin{array}{l}\text { Lital A-T8E51 } \\
(12.5 \mathrm{~mm} \text { thick })\end{array}$ & $\begin{array}{l}\text { Lital A-T8E51 } \\
(8 \mathrm{~mm} \text { thick })\end{array}$ & $\begin{array}{l}\text { Lital A-T6 } \\
\text { (3 mm thick) }\end{array}$ & $\begin{array}{l}\text { Lital C-T81 } \\
(1.6 \mathrm{~mm} \text { thick })\end{array}$ & $\begin{array}{l}\text { Lital C-T3 } \\
(1.6 \mathrm{~mm} \text { thick })\end{array}$ \\
\hline Degree of aging & Peak-aged & Peak-aged & Peak-aged & $\begin{array}{l}\text { Near } \\
\text { peak-aged }\end{array}$ & Under-aged \\
\hline $\begin{array}{l}\text { Degree of recrystal- } \\
\text { lization }\end{array}$ & PR & PR & PR & $\mathbf{R}$ & $\mathbf{R}$ \\
\hline $\begin{array}{l}\text { Crystallographic } \\
\text { texture }\end{array}$ & $\begin{array}{l}\text { Strong, cross- } \\
\text { rolled }\end{array}$ & $\begin{array}{l}\text { Strong, } \\
\text { straight-rolled }\end{array}$ & $\begin{array}{l}\text { Strong, } \\
\text { straight-rolled }\end{array}$ & - & - \\
\hline $\begin{array}{c}\text { Maximum drop in } \\
0.2 \% \text { YS }(\%)\end{array}$ & 21 & 21 & 23 & 13 & 6 \\
\hline $\begin{array}{l}\text { Maximum drop in } \\
\text { UTS }(\%)\end{array}$ & 14 & 16 & 12 & 1 & -1 \\
\hline $\begin{array}{l}\text { Maximum increase } \\
\text { in elongation }(\%)\end{array}$ & 113 & 30 & - & 87 & 12 \\
\hline
\end{tabular}

with those reported for Al-Li 8090 alloy products (Peters et al 1985, 1986a, b; Fox et al 1986; Palmer et al 1986). The calculation of Schmid factors as a function of orientation with respect to the rolling direction predicts that in these $\mathrm{Al}-\mathrm{Li}$ alloys the minimum in tensile strength and maximum in tensile ductility occur at orientations $50-60^{\circ}$ to the rolling direction (Peters et al 1985; Fox et al 1986). In a recent study conducted on 8090 and $8091 \mathrm{Al}-\mathrm{Li}$ alloys, Tempus et al (1991) predicted similar variation in tensile anisotropy through calculations based on the Taylor and Sachs models. The observed anisotropy in the present study can be understood on similar lines.

The degree of aging is seen to have a moderate effect on the anisotropy in strength, though the same influences the ductility significantly. In the case of Lital $\mathrm{C}$ sheets, the alloy in T81 condition shows a higher degree of anisotropy in yield strength as compared to that in T3 condition (table 3). Engler and Lucke (1991) observed that the precipitation stage that emerges with artificial aging changes the crystallographic texture of $8090 \mathrm{Al}-\mathrm{Li}$ alloy. The observed effect of degree of aging on the anisotropy may once again be attributed to the associated crystallographic texture.

The Lital C sheets in either of the heat-treated conditions show relatively lower degree of anisotropy in tensile properties when compared to the other $\mathrm{Al}-\mathrm{Li}$ alloy products considered here. This could be attributed primarily to the lower degree of mechanical fibring. The Lital $\mathrm{C}$ sheets possess near recrystallized grain structure coupled with low inclusion constant, no appreciable precipitate free zones (PFZs) and the absence of PFZ-associated coarse equilibrium precipitates (see table 1). However, the strength levels of recrystallized alloys, in general, are lower as compared to the partially or fully unrecrystallized alloys. Recrystallization, therefore, imparts isotropy in tensile properties at the cost of strength.

\subsection{Low cycle fatigue}

The variation of fatigue life with plastic strain amplitude at half-life, generally referred to as Coffin-Manson (C-M) plot, is shown in figure 3 for the $12.5 \mathrm{~mm}$ thick plate in 


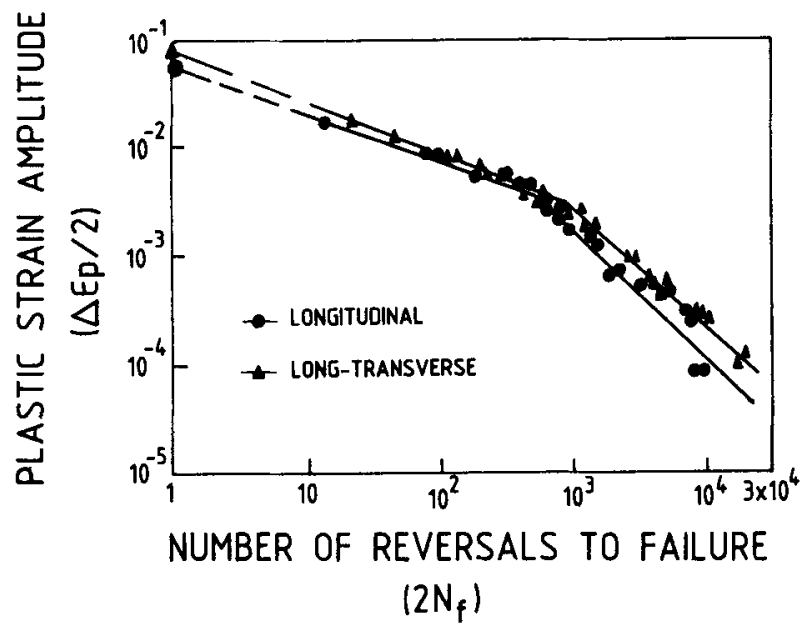

Figure 3. Coffin-Manson (C-M) plots for longitudinal and long-transverse test directions.

L and LT directions. The alloy exhibits superior fatigue resistance in the LT direction as compared to the $\mathrm{L}$ direction. The fatigue life in LT direction at any particular strain amplitude is $40-100 \%$ higher than that in the $\mathrm{L}$ direction. The variation in resistance against strain-controlled fatigue bears parallelism with tensile ductility, as expected. The alloy in LT direction possesses higher ductility (7\%) as compared to that in $\mathrm{L}$ direction $(5.4 \%)$.

Studies on the low cycle fatigue of $8090 \mathrm{Al}-\mathrm{Li}$ alloys are limited to microstructural effects and test environment (Coyne et al 1981; Srivatsan and Coyne 1986a,b; Srivatsan 1988). In a different study conducted on extruded bars of $8090 \mathrm{Al}-\mathrm{Li}$ alloy, Khireddine et al (1989) reported considerable anisotropy in LCF resistance. The alloy exhibited superior LCF resistance at core section in longitudinal direction as compared to that at the surface sections in L direction and to that at the core section of LT direction. The observed anisotropy has been attributed to the variation in grain size as well as crystallographic texture.

The $12.5 \mathrm{~mm}$ thick Lital-A alloy in both the test orientations exhibited a transition in $\mathrm{C}-\mathrm{M}$ plots at a strain $\Delta \varepsilon_{p} / 2 \simeq 2 \times 10^{-3}$. A detailed analysis revealed that the transition is associated with a gradual change in deformation and fracture modes (Eswara Prasad et al 1989). With increase in strain amplitude, the fracture mode changes from higher energy transgranular shear to lower energy ductile intergranular fracture. Highly localized plastic deformation due to shearing of $\mathrm{Al}_{3} \mathrm{Li}\left(\delta^{\prime}\right)$ precipitates at higher strain amplitudes results in intergranular fracture. These features were found to be common for specimens tested in both L and LT test directions.

\subsection{Strength differential under monotonic and cyclic conditions}

Cyclic stress response behaviour of 8090 alloy plate of $12.5 \mathrm{~mm}$ thickness in T8E51 condition analysed in terms of the variation of only tensile $\left(\sigma_{T}\right)$ or only compressive $\left(\sigma_{c}\right)$ stress amplitude with number of cycles revealed the occurrence of strength differential (S-D) (Eswara Prasad et al 1992). The variation of S-D with plastic strain for the three test directions ( $\mathrm{L}, \mathrm{L}+45^{\circ}$ and $\mathrm{LT}$ ) is shown in figure 4. For cyclic loading 


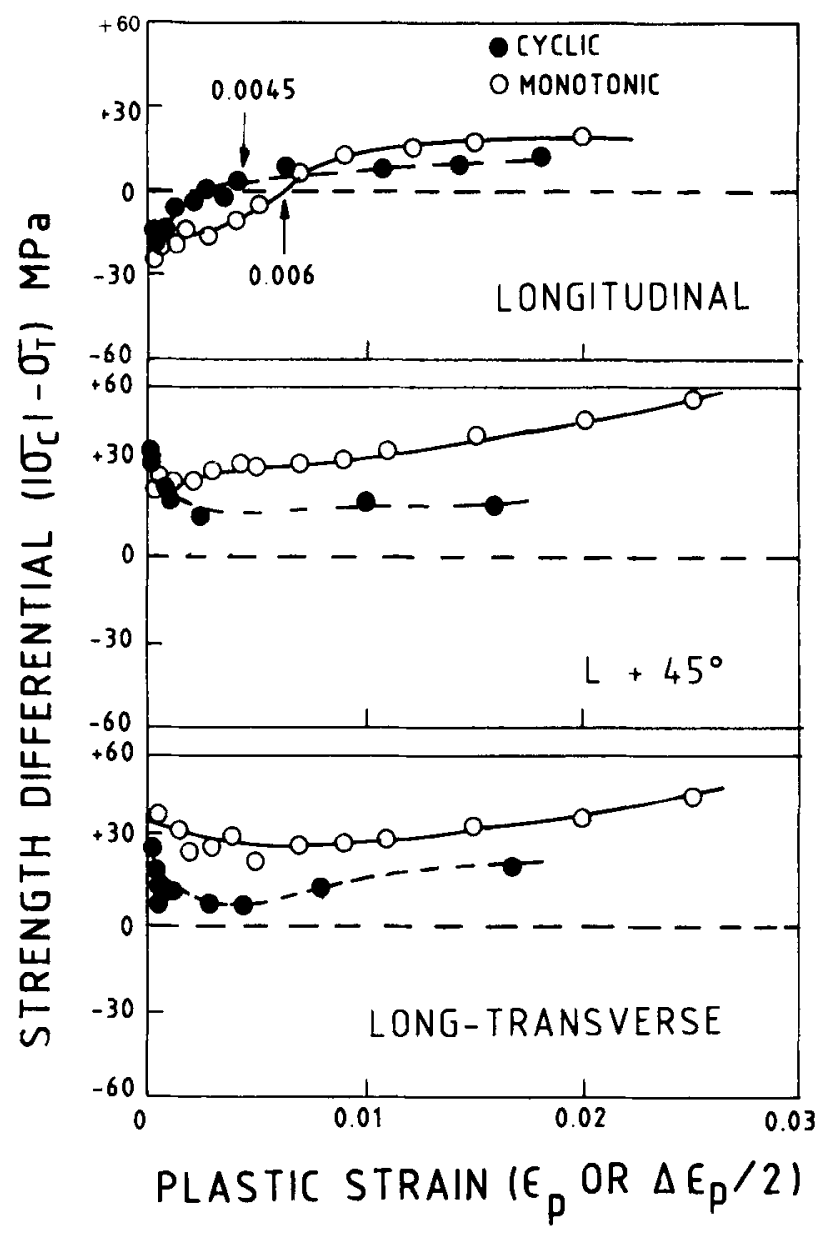

Figure 4. Variation of strength differential with plastic strain under monotonic and cyclic loading conditions in $\mathrm{L}, \mathrm{L}+45^{\circ}$ and $\mathrm{LT}$ test directions.

conditions, the strength differential $\left(\left|\sigma_{c}\right|-\sigma_{T}\right)$ at half-life is plotted against the corresponding plastic strain amplitude $\left(\Delta \varepsilon_{p} / 2\right)$. On the other hand, the monotonic strength differential data are derived from pure tension and compression tests using specimens of low cycle fatigue specimen geometry. The data revealed an orientation dependent S-D effect. The stress amplitude in compression $\left(\sigma_{c}\right)$ is higher than that in tension $\left(\sigma_{T}\right)$, depicting a normal S-D effect at all strain levels in the $L+45^{\circ}$ and long-transverse directions. A similar behaviour was observed at strain amplitudes $\Delta \varepsilon_{p} / 2>4.5 \times 10^{-3}$ in the longitudinal direction, for which, at lower strains, the S-D is more than compensated by the Bauschinger effect. The $2-3 \%$ tensile prestretch given to the material as part of thermomechanical treatment results in Bauschinger effect, which obscures S-D effect at lower strains in L direction. This study explains the behaviour generally reported but not clearly explained in literature (Lee et al 1990) regarding lower compressive yield strength in $\mathrm{L}$ direction of $\mathrm{Al}-\mathrm{Li}$ alloys with a prior history of stretch during processing.

The trends in S-D are found to be similar under cyclic and monotonic loading conditions. However, a comparison between the cyclic and monotonic S-D data 
presented in figure 4, brings out two aspects. First, the cross-over of the cyclic S-D from a negative to positive value in the case of $\mathrm{L}$ direction occurs at a lower strain level $\left(\Delta \varepsilon_{p} / 2=4.5 \times 10^{-3}\right)$ as compared to monotonic loading $\left(\varepsilon_{p}=6 \times 10^{-3}\right)$. Secondly, the magnitude of cyclic S-D at any particular strain level is nearly $20-40 \%$ lower than that under monotonic conditions. Among the three test directions considered, the $S-D$ is of largest magnitude in the $L+45^{\circ}$ direction.

Several explanations for the $\mathrm{S}-\mathrm{D}$ effect based on residual stresses, microcracks, interactions between dislocations and interstitial solute atoms and a stress concentration at the particle-matrix interface have been proposed in the literature (Leslie and Sober 1967; Hirth and Cohen 1969, 1970; Kalish and Cohen 1969; Olsen and Ansell 1969; Chait 1972). Of these, two mechanisms, namely (i) based on a stress intensification at the matrix-particle interface suggested by Olsen and Ansell (1969) and (ii) based on dislocation-solute atom interactions proposed by Hirth and Cohen $(1969,1970)$ appear relevant here. To investigate the applicability of these two explanations, the S-D data were obtained for $12.5 \mathrm{~mm}$ thick plate in four different heat-treated conditions, viz. the solution-treated, the peak-aged (T6), the overaged (T7) and the as-received stretch plus peak-aged (T8E51) conditions. Detailed analysis of the data revealed (Eswara Prasad et al 1992) that the S-D observed in the present alloy cannot be explained in terms of either the solute-dislocation interactions or the stress intensification at the particle-matrix interface.

\subsection{Anisotropy in fracture resistance}

The plane-strain fracture toughness $\left(K_{I c}\right)$ values obtained for $\mathrm{Al}-\mathrm{Li}$ alloys with different notch orientations (see figure 5) are listed in table 4 . The $12.5 \mathrm{~mm}$ thick plate possesses nearly $75 \%$ higher $K_{I c}$ in the L-T orientation as compared to that in the T-L orientation. The fractured surfaces also exhibit considerable differences in the two test orientations in terms of the degree of delamination. The height of delaminated ridges is found to be significantly higher $(1.5-3 \mathrm{~mm})$ in the $L-T$ orientation as compared to that in the $\mathrm{T}-\mathrm{L}$ orientation $(0.2-0.5 \mathrm{~mm})$. Considerably higher degree of anisotropy in fracture resistance of $\mathrm{Al}-\mathrm{Li}$ alloys is again evident when the $K_{I c}$ data obtained in S-L or S-T orientations are compared with that in L-T orientation (Venkateswara Rao and Ritchie 1988). The fracture toughness $\left(K_{I c}\right)$ values in S-T

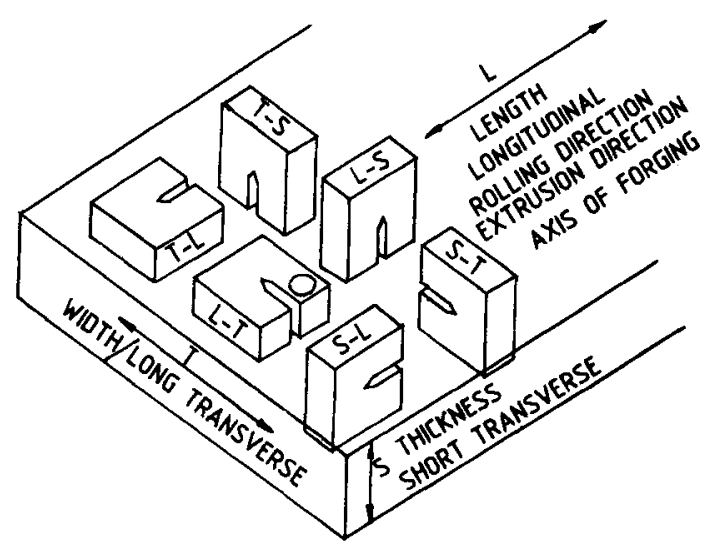

Figure 5. Crack plane orientation code for plate and sheet products. 
Table 4. Fracture toughness data of $\mathrm{Al}-\mathrm{Li}-\mathrm{Cu}-\mathrm{Mg}$ alloys.

\begin{tabular}{|c|c|c|c|c|c|}
\hline $\begin{array}{l}\text { Alloy } \\
\text { designation }\end{array}$ & $\begin{array}{c}\text { Crack } \\
\text { plane } \\
\text { orientation }\end{array}$ & $\begin{array}{c}0.2 \% \mathrm{YS} \\
(\mathrm{MPa})\end{array}$ & $\begin{array}{c}K_{I c} \text { or } K_{c} \\
(\mathrm{MPa} \sqrt{\mathrm{m}})\end{array}$ & $\begin{array}{c}\text { Thickness } \\
\text { required for } \\
\text { valid } K_{I c}(\mathrm{~mm})\end{array}$ & $\begin{array}{l}\text { Nature of load- } \\
\text { COD curve }\end{array}$ \\
\hline $\begin{array}{l}\text { Alcan } 8090 \\
\text { plate }(12.5 \mathrm{~mm} \text { thick })\end{array}$ & $\begin{array}{l}\mathrm{L}-\mathrm{T} \\
\mathrm{T}-\mathrm{L} \\
\mathrm{S}-\mathrm{L}^{*}\end{array}$ & $\begin{array}{c}485 \\
465 \\
-\end{array}$ & $\begin{array}{l}28 \\
16 \\
13\end{array}$ & $\begin{array}{l}8 \cdot 4 \\
3 \cdot 2 \\
1 \cdot 8\end{array}$ & $\begin{array}{l}\text { Gradual load drop } \\
\text { Sudden load drop } \\
\text { Sudden load drop }\end{array}$ \\
\hline $\begin{array}{l}\text { Alcan } 2090^{*} \\
-T 8 E 41 \text { plate }\end{array}$ & $\begin{array}{l}\mathrm{L}-\mathrm{T} \\
\mathrm{T}-\mathrm{L} \\
\mathrm{S}-\mathrm{L} \\
\mathrm{S}-\mathrm{T}\end{array}$ & $\begin{array}{l}552 \\
548 \\
372 \\
372\end{array}$ & $\begin{array}{l}36 \\
24 \\
17 \\
16\end{array}$ & $\begin{array}{r}10.6 \\
4.8 \\
5.2 \\
4.6\end{array}$ & - \\
\hline $\begin{array}{l}\text { Alcan } 8090- \\
\text { Lital A } \\
\text { sheet ( } 3 \mathrm{~mm} \text { thick) }\end{array}$ & $\begin{array}{l}\mathrm{L}-\mathrm{T} \\
\mathrm{T}-\mathrm{L}\end{array}$ & $\begin{array}{l}456 \\
426\end{array}$ & $\begin{array}{l}51^{\dagger} \\
50^{\dagger}\end{array}$ & - & $\begin{array}{l}\text { Rising R-curve } \\
\text { Flat R-curve }\end{array}$ \\
\hline
\end{tabular}

*Data from Venkateswara Rao and Ritchie (1988)

'Plane-stress fracture toughness $\left(K_{c}\right)$

and S-L orientations (see figure 5) are more than $50 \%$ as compared to the $K_{I c}$ value in $\mathrm{L}-\mathrm{T}$ orientation (table 4). Such an anisotropy in fracture resistance of $\mathrm{Al}-\mathrm{Li}$ alloys has been attributed to microstructural features. The anisotropic, nearly unrecrystallized grain structure and marked deformation texture lead to easy delamination in the thickness direction (Venkateswara Rao and Ritchie 1988; Roven et al 1990). In a recent study on $8090 \mathrm{Al}-\mathrm{Li}$ alloy plate Lynch (1991) has shown that double aging treatment involving reaging, after initial artificial aging, at high temperatures of $200-210^{\circ} \mathrm{C}$ (rapid heating to the reaging temperature) for shorter durations of up to $300 \mathrm{~s}$, significantly increases toughness in the thickness (S-L) direction with only a marginal loss in strength and thereby reduces the anisotropy in fracture resistance. The beneficial effect of double aging treatment has been attributed to the decrease in the extent of lithium segregation at the grain boundaries.

The plane-stress fracture toughness $\left(K_{c}\right)$ values obtained in the $\mathrm{L}-\mathrm{T}$ and $\mathrm{T}-\mathrm{L}$ orientations for Lital A sheet of $3 \mathrm{~mm}$ thickness are listed in table 4. The alloy in both the test orientations possesses nearly the same $K_{c}$ value. However, the nature of the $K_{R}-\Delta a$ plots (known as $R$-curves) is different for the two test directions. The alloy exhibits progressively rising $R$-curve with deflected crack path in the L-T orientation as against the flat $R$-curve behaviour in the $\mathrm{T}-\mathrm{L}$ orientation with straight crack path (figure 6). The increased resistance to crack extension in $\mathrm{L}-\mathrm{T}$ orientation as compared to the $\mathrm{T}-\mathrm{L}$ orientation can be explained using a mixed-mode analysis (Kamat and Eswara Prasad 1990). The deflected cracks in $\mathrm{L}-\mathrm{T}$ orientation are assumed to be initially inclined cracks with the inclination angle being the same as deflection angle, $\theta$. The analysis shows that

or

$$
\left(K_{R}\right)_{\text {Deflected crack }}=\left(K_{R}\right)_{\text {Undeflected crack }} \times \sec ^{\frac{1}{3}} \theta
$$

$$
\left(K_{R}\right)_{\mathrm{L} \text { T orientation }}=\left(K_{R}\right)_{\mathrm{T} \text { L orientation }} \times \sec ^{\frac{1}{2}} \theta
$$

As the angle of deflection $(\theta)$ increases, the fracture resistance in $\mathrm{L}-\mathrm{T}$ orientation increases. The theoretically predicted $R$-curve in L-T orientation (figure 6a), using the $K_{R}-\Delta a$ data obtained for undeflected crack in $\mathrm{T}-\mathrm{L}$ orientation and the deflection 

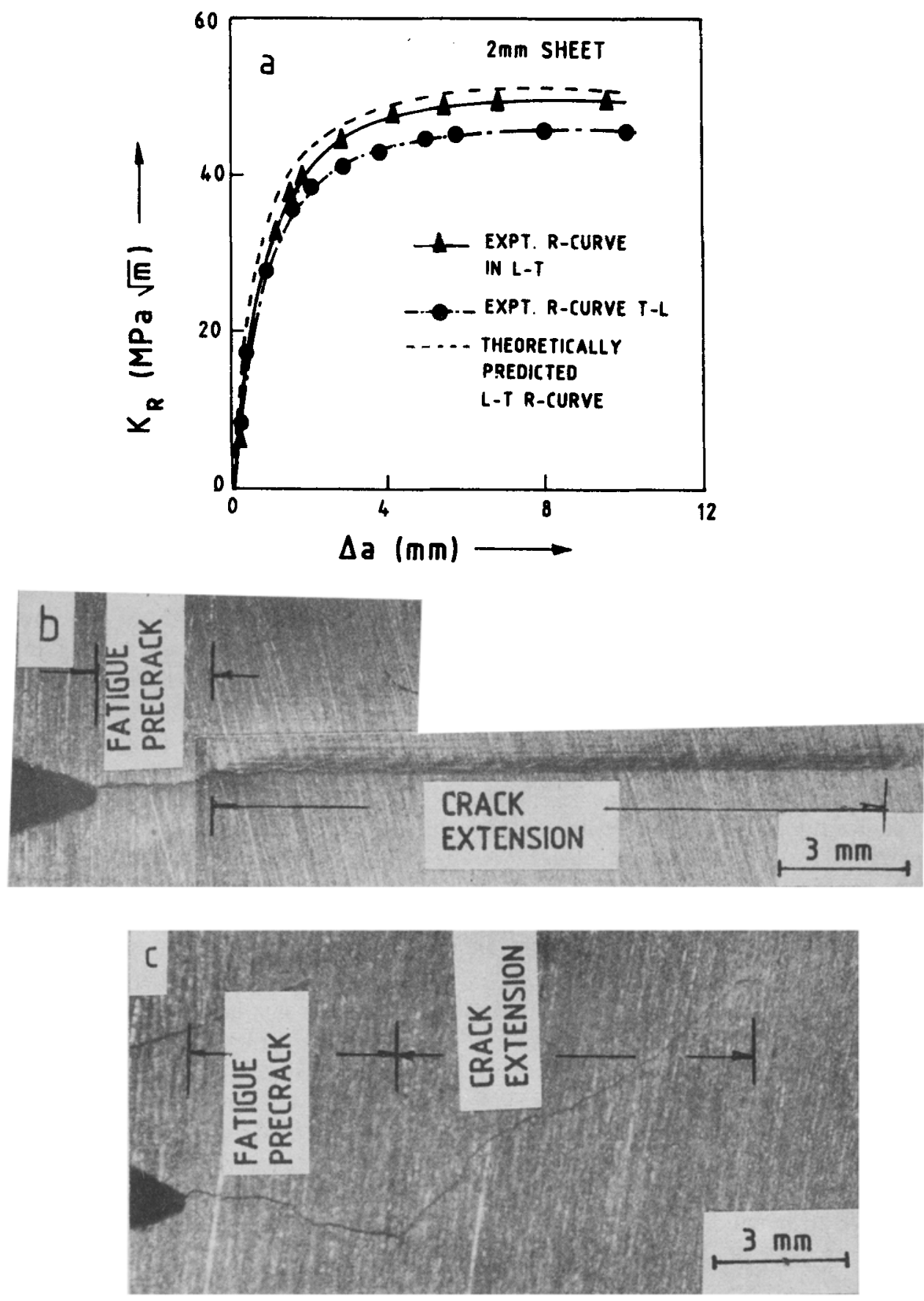

Figure 6. (a) $K_{R}-\Delta a$ plots of Lital A sheet ( $2 \mathrm{~mm}$ thick) and the corresponding crack path morphologies in (b) $\mathrm{T}-\mathrm{L}$ and (c) $\mathrm{L}-\mathrm{T}$ test directions.

angle measured for L-T orientation, is seen to match well with the experimentally obtained $R$-curve (Kamat and Eswara Prasad 1990). The progressively increasing fracture resistance in the $\mathrm{L}-\mathrm{T}$ orientation can therefore be attributed to the crack 
path deflection. Metallographic observations reveal that the cracks follow the shear bands in $\mathrm{L}-\mathrm{T}$ orientation and get deflected constantly. The shear bands are formed along $\{111\}$ planes which are grossly oriented at $45-55^{\circ}$ to the rolling direction. On the other hand, the cracks in $\mathrm{T}-\mathrm{L}$ orientation follow the high angle grain boundaries and result in relatively straight crack paths (Eswara Prasad et al 1991).

\section{Conclusions}

Marked anisotropy in mechanical properties, namely the tensile, fatigue and fracture, has been observed in quaternary $\mathrm{Al}-\mathrm{Li}-\mathrm{Cu}-\mathrm{Mg}$ alloys in both plate and sheet product forms. The extent of anisotropy was seen to be as high as $110 \%$ in tensile ductility and more than $50 \%$ in fracture resistance measured in terms of $K_{I c}$. Such an anisotropy in mechanical properties has primarily been attributed to the nearly unrecrystallized pancake microstructure and strong crystallographic texture.

\section{Acknowledgements}

The authors are grateful to Dr P Rama Rao, for constant encouragement and keen interest in this work. Thanks are due to Prof. V Kutumba Rao for valuable comments on the manuscript and Dr K N Raju and Dr R Sunder for providing material for conducting these studies. The help received from Mr K S Prasad in conducting the microstructural investigations and $\operatorname{Dr} R \mathbf{K}$ Basu in texture analysis is gratefully acknowledged.

\section{References}

Baker C, Gregson P J, Harris S J and Peel C J (ed.) 1986 in Aluminium-lithium alloys III (London: The Institute of Metals)

Behnood N and Evans J T 1989 Acta Metall. 37687

Chait R 1972 Metall. Trans. 3365

Coyne E J, Sanders T H and Starke E A 1981 in Aluminium-lithium alloys, Proc. First Inter. Al-Li Conf., (Warrendale PA: The Metall. Soc. of AIME) p. 293

Dinsdale K, Noble B, Harris S J and Gregson P J 1988 Mater. Sci. Engg. 10175

Doorbar P J, Borradaile J B and Driver D 1986 in Aluminium-lithium alloys $I I I$, (eds) C Baker, P J Gregson, S J Harris and C J Peel (London: The Institute of Metals) p. 496

Engler O and Lucke K 1991 Mater. Sci. Engg. A148 15

Eswara Prasad N, Malakondaiah G, Raju K N and Rama Rao P 1989 in Advances in fracture, Proc. Int. Conf. Fracture (ICF7) (eds) K Salama, K Ravi Chandar, D M R Taplin and P Rama Rao, Vol. 2, p. 1103

Eswara Prasad N, Kamat S V and Malakondaiah G 1991 in Aluminium strategies for the nineties and beyond, Proc. 2nd Int. Conf. Aluminium, (Incal 91) (eds) E S Dwarakadasa, S Seshan and K P Abraham (Bangalore: Aluminium Assoc. of India) p. 613

Eswara Prasad N, Malakondaiah G and Rama Rao P 1992 Mater. Sci. Engg. A150 221

Forsyth P J E and Stubbington C A 1975 Metals Technol. 2158

Fox S, Flower H M and McDarmaid DS 1986 in Aluminium alloys - their physical and mechanical properties, (eds) E A Starke and T H Sanders (Warly, UK: Engineering Materials Advisory Service) Vol. II, p. 939

Gregson P J and Flower H M 1985 Acta Metall. 33527

Gregson P J, McDarmaid D S and Hunt E 1988 Mater. Sci. Technol. 4713

Hirth J P and Cohen M 1969 J. Matals 21 27A

Hirth J P and Cohen M 1970 Matall. Trans. 13

Jata K V and Starke E A 1986 Met. Trans. A17 1011 
Kalish D and Cohen M 1969 Trans. Am. Soc. Met. 62353

Kamat S V and Eswara Prasad N 1990 Scr. Metall. Mater. 241907

Khireddine D, Rahouadj R and Clavel M 1989 Acta Metall. 37191

Lee E W and Kim N J 1989 in Aluminium-lithium allovs, Proc. 5th Int. Aluminium-lithium Conf., (eds)

T H Sanders and E A Starke (Birmingham, UK: Materiais \& Components Engg. Pub. Ltd.) Vol. II, p. 809

Lee E W, Neu C E and Kazol J 1990 J. Metals 4211

Leslie W C and Sober R J 1967 Trans. Am. Soc. Met. 60459

Lynch S P 1991 Mater. Sci. Engg. A136 25, 45

Olsen R J and Ansell G S 1969 Trans. Am. Soc. Met. 62711

Palmer I G, Miller W S, Lloyd D J and Bull M J 1986 in Aluminium-lithium alloys III (eds) C Baker, P J Gregson, S J Harris and C J Peel (London: The Institute of Metals) p. 565

Peel C J, Evans B and McDarmaid D 1986 in Aluminium-lithium alloys III (eds) C Baker, P J Gregson, S J Harris and C J Peel (London: The Institute of Metals) p. 26

Peel C J, Evans B and McDarmaid D J 1987 Metals Mater. 3449

Peters M, Welpmann K and Sanders T H 1985 in Proc. 3rd Conf. E-MRS on advanced materials R \& D for transport, Strasbourg

Peters M, Eschweiler J and Welpmann K 1986a Scr. Metall. 20259

Peters M, Welpmann K, Zink W and Sanders T H 1986b in Aluminium-lithium alloys III (eds) C Baker, P J Gregson, S J Harris and C J Peel (London: The Institute of Metals) p. 239

Roven H J, Starke E A, Sodahl O and Hjelen J 1990 Scr. Metall. Mater. 24421

Smith A F 1987 J. Phys. (Paris) 48 C3-629

Srivatsan T S 1988 Inter. J. Fatigue 1091

Srivatsan T S and Coyne E J 1986a Inter. J. Fatigue 8201

Srivatsan T S and Coyne E J 1988b in Conf. Proc. Int. Sym. for testing and fracture analysis, (Metal Park, Ohio: ASM Inter.) p. 281

Srivatsan T S and Coyne E J 1989 Mater. Sci. Technol. 5548

Takahashi K, Manakawa K and Ouchi C 1987 J. Phys. (Paris) 48 C3-163

Tempus G, Calles W and Scharf G 1991 Mater. Sci. Technol. 7937

Venkateswara Rao K T and Ritchie R O 1988 Mater. Sci. Technol. 5882

Welpmann K, Peters M and Sanders T H 1984 Aluminium 60 735, 846

Wilson D V 1975 Metals. Technol. 28 